\title{
Impacts of Soil Microbiome Variations on Root Colonization by Fungi and Bacteria and on the Metabolome of Populus tremula $\times$ alba
}

\author{
L. Mangeot-Peter, ${ }^{1}$ T. J. Tschaplinski, ${ }^{2}$ N. L. Engle, ${ }^{2}$ C. Veneault-Fourrey, ${ }^{1}$ F. Martin, ${ }^{1,3}$ and A. Deveau ${ }^{1, \dagger}$ \\ ${ }^{1}$ Université de Lorraine, INRAE, UMR IAM, 54280 Champenoux, France \\ ${ }^{2}$ Biosciences Division, Oak Ridge National Laboratory, Oak Ridge, TN 37831, U.S.A. \\ ${ }^{3}$ Beijing Advanced Innovation Center for Tree Breeding by Molecular Design, Beijing Forestry University, Haisian District, Beijing, China
}

Accepted for publication 12 March 2020.

\section{ABSTRACT}

Trees depend on beneficial interactions between roots and soil microbes for their nutrition and protection against stresses. The soil microbiome provides the main reservoir of microbes for root colonization and is subject to natural variations that can affect its composition. It is not clear whether the tree's root system is able to buffer the natural variations occurring in the soil microbiome to capture a stable and effective microbiome or whether these variations affect its microbiome to impact its physiology. To address this question, we planted cuttings of Gray Poplar (Populus tremula $\times$ alba clone 717-1B4) in natural soil taken from a poplar stand under the same tree over two consecutive years and grew them in a greenhouse. We analyzed the soil and root microbiomes by high throughput Illumina MiSeq sequencing of fungal rDNA internal transcribed spacer and bacterial 16S rRNA amplicons and we characterized the root metabolome by gas chromatography-mass spectrometry. Soil and root microbial communities significantly shifted over the 2 years. A modification of the balance between endophytes, saprophytes, and mycorrhizal fungi occurred in the roots as well as a replacement of some dominant operational taxonomic units by others. These modifications were correlated with a significant alteration of the levels of about $10 \%$ of primary and secondary metabolites, suggesting that natural fluctuations in soil microbial communities can have a profound impact on tree root metabolism and physiology. Tree roots functioning may thus be indirectly strongly affected by the effects of future extreme climatic variations on the soil microbiome.

Keywords: endophyte, ectomycorrhizal fungi, metabarcoding, metabolome, microbiome, Populus, symbiosis
Roots are heavily colonized by complex communities of microorganisms (the so-called root microbiome) as a result of the massive release of carbon compounds in the rhizosphere that provides energy sources to a multitude of soil microbes. Among the numerous members of the root-associated microbiome, fungi and bacteria dominate in terms of abundance and diversity, and play key roles in plant development and health (Lladó et al. 2017). Some of

\section{Corresponding author: A. Deveau: aurelie.deveau@inrae.fr}

Funding: This work was supported by the Agence Nationale de la Recherche (ANR11-LABX-0002-01) through the Laboratory of Excellence ARBRE and by the PlantMicrobe Interfaces Scientific Focus Area in the Genomic Science Program, the Office of Biological and Environmental Research in the U.S. Department of Energy Office of Science. Oak Ridge National Laboratory is managed by UT-Battelle, LLC, for the U.S. Department of Energy Office of Science (DE-AC05-00OR22725). L. MangeotPeter was supported by "Contrat Doctoral" from the French Ministère de l'éducation nationale et de la recherche.

*The $\boldsymbol{e}$-Xtra logo stands for "electronic extra" and indicates that three supplementary figures and supplementary tables are published online.

The author(s) declare no conflict of interest.

(C) 2020 The American Phytopathological Society these microorganisms, such as mycorrhizal symbionts, benefit plants by promoting plant nutrition (Jacoby et al. 2017) and resistance to biotic and abiotic stress (Meena et al. 2017; Naylor and Coleman-Derr 2018), while other microorganisms, such as pathogens and parasites, are detrimental to plants (Raaijmakers et al. 2009). The host plants and their microbiomes form a complex ecosystem in which many interacting species contribute to the overall functioning and stability of the system (Hacquard and Schadt 2015).

The composition (i.e., identity of taxa) and the richness (i.e., number of taxa) of the root microbiome are highly dynamic and vary according to nutrient availability, physico-chemical environmental parameters, and biotic interactions (Haas et al. 2018; Lladó et al. 2017). If edaphic parameters and the activities of the host plant are both involved in the structuring of the root microbiome, opinions remain divided on the relative importance of these two factors in driving the root microbiome composition (Lareen et al. 2016). On one hand, host factors such as root exudate quality and quantity, and plant secondary metabolites affect the colonization of roots by microorganisms (Berg and Smalla 2009). Host factors depend on the genotype of the plant, but are also modulated by extrinsic factors, such as plant and soil management or environmental 
variation. For instance, atmospheric $\mathrm{CO}_{2}$ enrichment stimulates tree physiology and modifies the quantity and quality of root exudates (Pritchard 2011). On the other hand, environmental factors such as soil properties (e.g., $\mathrm{pH}$ and nitrogen availability) and climate (e.g., humidity and temperature) affect the survival and the activities of microorganisms present in the surrounding bulk soil that serve as a reservoir, and thus their ability to colonize roots (Fierer 2017). Finally, stochastic processes including ecological drift and colonization history can also affect the root microbiome composition (Emerson and Gillespie 2008).

As a complex community, the plant root microbiome has been shown to adapt rapidly to abiotic limitations, to alleviate host stress and to modify plant growth (Lau and Lennon 2012). Such abilities open opportunities for microbial engineering to optimize plant growth and reduce the negative effects of stressors linked to climate change (Farrar et al. 2014; Meena et al. 2017). Yet this requires (i) identifying how we can manipulate and manage the soil microbiome, (ii) understanding how the root microbiome composition and activities are regulated, and (iii) understanding how its composition impacts the plant host biology. Such questions are currently the subjects of extensive studies on agronomic annual crop species (Chaparro et al. 2012), but much less is known regarding woody perennials, including trees and shrubs, despite their importance for terrestrial ecosystems, climate change mitigation, and forestry. Trees are long-lived woody perennial plants that manage nutrient allocations, notably to the roots, in a very different way compared with Arabidopsis thaliana, the model herbaceous species, or annual crop species (Nehls 2008). Moreover, in contrast to crops, ectomycorrhizal fungi are a major component of tree microbiome in temperate and boreal forests (Uroz et al. 2016), while most studies of the plant microbiome currently focus on bacterial communities (Mendes et al. 2013; Van Der Heijden et al. 2008). Endophytic and saprophytic fungi also colonize trees but their roles remain elusive with a few exceptions (Liao et al. 2019). In addition, the mutualistic symbiosis between tree roots and mycorrhizal fungi shape specific communities of bacteria that tend, on the whole, to be beneficial to their hosts and that differ from those of nonmycorrhizal roots (Frey-Klett et al. 2007).

There is an important variability between microorganisms in their functional capacities with redundancies, synergies, and antagonisms (Chaparro et al. 2012), as well as in their ability to resist stress (Gehring et al. 2017; Naylor and Coleman-Derr 2018). For instance, species of ectomycorrhizal fungi differ in their abilities to provide nitrogen to their hosts (Pena and Polle 2014). Nevertheless, a shift in the taxonomic composition of microbial communities can be functionally neutral, due, in part, to functional redundancies of species as shown in the rhizosphere of beech (Fagus sylvatica L.) (Colin et al. 2017). In this study, it has been shown that the operational taxonomic unit (OTU) composition of bacterial communities associated to beech trees along a toposequence substantially vary, but the nutrition-related functions remain stable. While there is a good understanding of the parameters influencing the taxonomic composition of the soil, and to a lesser extent of the root microbiome, how much functional redundancy buffers these variations is poorly known. Neither do we know the extent to which the degree of change in the soil microbiome affects the root microbiome and therefore tree metabolism. In the present study, we aimed to assess whether local shifts in soil microbiome composition potentially due to year-to-year environmental variations influence the composition of the rootassociated microbiome, and consequently, the root metabolism. We used the Gray Poplar, Populus tremula $\times$ alba, as a model system. Populus has become a model to study genetics and biology of woody perennials (Tuskan et al. 2006), and more recently, tree microbiome interactions (Cregger et al. 2018; Gottel et al. 2011; Shakya et al. 2013; Veach et al. 2019). Populus have the capacity to form both arbuscular mycorrhizal and ectomycorrhizal symbioses. In addition to mycorrhizal symbionts, Populus is also host to a variety of beneficial bacterial and fungal endophytes (Gehring et al. 2006; Hacquard and Schadt 2015; Timm et al. 2018). Microbial community members from Populus have been shown to enhance tree growth and development (Timm et al. 2016). The composition and structure of the root microbiome shift across environmental gradients (Gottel et al. 2011; Shakya et al. 2013; Veach et al. 2019) but also between Populus genotypes and species (Bonito et al. 2014; Veach et al. 2019). Differences in bacterial and fungal community composition and structure varied across season due to climatic fluctuations and tree physiology (Shakya et al. 2013).

In the present work, we hypothesized that potential natural shift in soil microbiome composition and structure could be also observed in roots, and therefore, alter the tree root metabolome. To test this hypothesis, we sampled soil in the same location near the same tree in a poplar plantation over 2 years and planted cuttings of Populus tremula $\times$ alba clone $717-1 \mathrm{~B} 4$ in pots filled with this soil. Cuttings were grown in a greenhouse under controlled conditions for one and a half months. We characterized the initial soil microbial communities as well as the soil- and root-associated fungal and bacterial communities after 10 days and 6 weeks of growth, using amplicon $16 \mathrm{~S}$ and internal transcribed spacer (ITS) rRNA genetargeted Illumina MiSeq sequencing. In parallel root metabolomes were assessed by gas chromatography-mass spectrometry (GC-MS) at the two time points of sampling.

\section{MATERIALS AND METHODS}

Plant and soil material. We used cuttings of Populus tremula $\times$ alba INRA 717-1B4 clone (Mader et al. 2016) harvested from a mother tree cultivated in the INRA poplar nursery located in Champenoux, France $\left(48^{\circ} 45^{\prime} 3^{\prime \prime} \mathrm{N} / 6^{\circ} 20^{\prime} 6^{\prime \prime} \mathrm{E}\right)$. The mother tree was pruned at the end of winter 2016 and 2017, and cuttings were stored at $4{ }^{\circ} \mathrm{C}$ until further use. Soil (clayey loamy soil type) was collected from an 18-year-old poplar stand planted with Populus trichocarpa $\times$ deltoides and located in Champenoux, France $\left(48^{\circ} 45^{\prime} 24^{\prime \prime} \mathrm{N} / 6^{\circ} 21^{\prime} 24^{\prime \prime} \mathrm{E}\right)$ after pruning of brambles and adventitious plants and litter removal with a rake. About 100 liters of top soil $(0$ to $15 \mathrm{~cm})$ were taken each year in the same location under the same tree on 9 June 2016 and on 3 July 2017. The tree was located in the heart of the stand and separated from the neighboring trees by a minimum of $3 \mathrm{~m}$. The same procedure was followed for two consecutive years: soil was stored in a greenhouse at room temperature for 3 days before being sieved at $2 \mathrm{~mm}$ and adjusted to $75 \%$ humidity. Three samples of soil of $5 \mathrm{~g}$ were collected and stored at $-20^{\circ} \mathrm{C}$ until DNA extraction. One sample of $50 \mathrm{~g}$ of soil was collected, dried at $30^{\circ} \mathrm{C}$ for 3 days, sieved at $2 \mu \mathrm{m}$, and stored at room temperature in an airtight container until physico-chemical analysis.

Soil physico-chemical properties. Soil analyses were performed using the LAS (Laboratoire d'Analyses des Sols) technical platform of soil analyses at INRA Arras, according to standard procedures, detailed online (https://www6.hautsdefrance.inrae.fr/las/Methodes$\mathrm{d}$-analyse). Exchangeable cations were extracted in either $1 \mathrm{M} \mathrm{KCl}$ (magnesium, calcium, sodium, iron, and manganese) or $1 \mathrm{M} \mathrm{NH}_{4} \mathrm{Cl}$ (potassium) and determined by inductively coupled plasma atomic emission spectroscopy (JY180 ULTRACE). The $1 \mathrm{M} \mathrm{KCl}$ extract was also titrated using an automatic titrimeter (Mettler TS2DL25) to assess exchangeable $\mathrm{H}^{+}$and aluminum cations $\left(\mathrm{Al}^{3+}\right)$. Total carbon, nitrogen, and phosphorus contents were obtained after combustion at $1,000^{\circ} \mathrm{C}$ and were determined using a Thermo Quest Type NCS 
2500 analyzer. The $\mathrm{pH}$ of the soil samples was measured in water at a soil to solution ratio of 1:2 (pH meter Mettler TSDL25). Exchangeable acidity was calculated by taking the sum of $\mathrm{H}^{+}$and $\mathrm{Al}^{3+}$. The cation-exchange capacity (CEC) was calculated by taking the sum of both extracted exchangeable base cations and exchangeable acidity. Soils collected at the beginning of the 2 years of experiment were called bulk soil T0 in this study (Supplementary Fig. S1).

Cultivation and sampling strategies. Populus tremula $\times$ alba INRA $717-1 \mathrm{~B} 4$ cuttings were maintained at $4^{\circ} \mathrm{C}$ until transfer to a greenhouse $\left(20^{\circ} \mathrm{C}, 16 \mathrm{~h}\right.$ light), where they were cultivated in a hydroponic system containing the full-strength Hoagland's nutrient solution (Hoagland and Arnon 1950) for 1 month in order to induce root formation and to homogenize root length of all cuttings. Cuttings with homogeneous root systems were then transferred in early summer (13 June 2016, seven cuttings and 6 July 2017, 12 cuttings, Supplementary Fig. S1) to 1-liter pots filled with soil previously taken from the poplar plantation (described previously). Experiments performed in 2016 and 2017 are further referred to as soil 1 and soil 2 . Humidity in pots was monitored and maintained at approximately $75 \%$ during the experiments. Two samplings were conducted both years to take into account the dynamic of root colonization by different microorganisms: the first after 10 days of growth (T1) and the second after 6.5 weeks of growth (T2). Indeed, bacteria, saprophytic fungi, and pathogenic fungi are able to colonize roots within a few days, while ectomycorrhizal fungi often require several weeks to establish a functional symbiosis (Marupakula et al. 2016; Smith and Read 2008).

Bulk soil samples were collected from each pot from an area free of roots and stored at $-20^{\circ} \mathrm{C}$ until DNA extraction. Soil collected at $\mathrm{T} 1$ and T2 were called bulk soil T1 and bulk soil T2 (Supplementary Fig. S1). Two representative parts of the total root system of each tree were harvested, cleaned with an $\mathrm{NaCl} 10 \mathrm{mM}$ solution and then with sterile water, frozen in liquid nitrogen, and stored at $-20^{\circ} \mathrm{C}$ until DNA extraction or at $-80^{\circ} \mathrm{C}$ until metabolomics analyses. Three trees were sampled at $\mathrm{T} 1$ in soil 1 , four at $\mathrm{T} 2$ in soil 1 , and six at both $\mathrm{T} 1$ and $\mathrm{T} 2$ in soil 2 (Supplementary Fig. S1).

DNA extraction, amplification, and Illumina MiSeq sequencing. To minimize DNA extraction bias, DNA was extracted in triplicate from the bulk soil. Approximatively $250 \mathrm{mg}$ of soil sample was used for each individual DNA extraction. DNA was extracted using the DNeasy PowerSoil Kit following the protocol provided by the manufacturer (Qiagen, Venlo, the Netherlands). Fifty milligrams of root tissue was crushed in liquid nitrogen, and DNA was extracted using the DNAeasy PowerPlant Kit (Qiagen). DNA were quantified with a NanoDrop 1000 spectrophotometer (NanoDrop Products, Wilmington, DE, U.S.A.).

A two-step PCR approach was chosen to barcode tag templates with frameshifting nucleotide primers (Lundberg et al. 2013). Primer mixtures for tagging bacterial amplicons were composed of four forward 515F (Universal, Chloroflexi, TM7, Nano; Supplementary Table S1) and two reverse 806R (Universal, Nano; Supplementary Table S1) primers screening the 16S rRNA V4 gene region in equal concentration $(0.1 \mu \mathrm{M})$ previously described by Cregger et al. (2018). Primer mixtures for tagging fungal amplicons were composed of six forward (ITS3NGS1, ITS3NGS2, ITS3NGS3, ITS3NGS4, ITS3NGS5, and ITS3NGS10; Supplementary Table S1) and one reverse (ITS4NGS; Supplementary Table S1) for ITS3-ITS4 rRNA region at equal concentration (0.1 $\mathrm{MM}$; Cregger et al. 2018). To inhibit plant material amplification, a mixture of peptide nucleotide acid (PNA) (Panagene, Korea) blockers were added in PCR reaction mixes. These PNA blockers targeted plant mitochondrial and chloroplast 16S rRNA genes (mtPNA_717-1B4, pPNA_717-1B4; Lundberg et al. 2013;
Supplementary Table S1) and plant ITS nuclear rRNA gene (ITSspacePNA_717-1B4; Cregger et al. 2018; Supplementary Table S1). The mitochondrial PNA (mtPNA_717-1B4; Supplementary Table S1) of Lundberg et al. (2013) was adjusted for a $1 \mathrm{bp}$ mismatch in Populus alba $\times$ tremula. PCR were performed for three replicates of each sample ( $2 \mu \mathrm{l}$ of isolated DNA at about $10 \mathrm{ng} / \mu \mathrm{l})$ using $2.5 \times$ Phusion flash high fidelity master mix (ThermoScientific) with $1.5 \mu$ l of forward and reverse primer mix, $0.75 \mu l$ of PNA probe, and $8.5 \mu \mathrm{l}$ of $0.2 \mu \mathrm{m}$ filtered UV-treated DNA-free water (Carl Roth, France) in a total reaction volume of $30 \mu \mathrm{l}$ per sample. Thermal cycler conditions for the primary PCRs for bacterial amplification were 30 cycles of $98^{\circ} \mathrm{C}$ for $5 \mathrm{~s}, 78^{\circ} \mathrm{C}$ for $10 \mathrm{~s}$, $52^{\circ} \mathrm{C}$ for $20 \mathrm{~s}$, and $72^{\circ} \mathrm{C}$ for $15 \mathrm{~s}$. Primary PCR condition for fungal amplification were 30 cycles of $98^{\circ} \mathrm{C}$ for $5 \mathrm{~s}, 78^{\circ} \mathrm{C}$ for $10 \mathrm{~s}, 55^{\circ} \mathrm{C}$ for $20 \mathrm{~s}$, and $72^{\circ} \mathrm{C}$ for $15 \mathrm{~s}$. PCR products without addition of microbial DNA (negative control), mock communities of known fungal or bacterial compositions were added as quality controls. Samples of $50 \mu \mathrm{l}(30 \mathrm{ng}$ of DNA per $\mu \mathrm{l}$ ) were sent for tagging and MiSeq Illumina Next Generation Sequencing (GeT PlaGe INRA sequencing platform, Toulouse, France). The raw data were deposited in the NCBI Sequence Read Archive (SRA) website (https:// www.ncbi.nlm.nih.gov/sra) under the SRA study accession numbers PRJNA548249 for 16S data and PRJNA548250 for ITS data.

Amplicon data processing and analysis. Bacterial sequences were further processed with FROGS (Find Rapidly OTU with Galaxy Solution) (Escudié et al. 2018) based on the Galaxy analysis platform (Afgan et al. 2016). Sequences were demultiplexed, dereplicated, sequence quality was checked, oligonucleotides, linker, pads and barcodes were removed from sequences, and sequences were filtered on additional criteria. Sequences were removed from data set, if nonbarcoded, if sequences exhibited ambiguous bases or did not match expectations in amplicon size. Remaining sequences were clustered into OTUs based on the iterative Swarm algorithm, then chimeras and singletons (OTUs containing only one sequence) were removed. Bacterial double affiliation was performed by blasting OTUs against SILVA database (Quast et al. 2013) and the ribosomal database project (RDP) classifier (Wang et al. 2007). OTUs with affiliation $<100 \%$ at the phylum level (indicated by an RDP bootstrap value of $<1$ ) and corresponding to chloroplasts or mitochondria were removed from the data set. OTUs at lower taxonomic ranks than the phylum level were considered as "unidentified" below when the RDP bootstrap value was $<0.70$. OTUs with high abundances in negative controls were excluded from further analysis and sequencing, and affiliation quality was evaluated based on the results obtained for the bacterial mock community.

Fungal sequences were processed as following. After demultiplexing and quality checking $(\mathrm{QC}$ quality score $=28$, minimal size $=$ $180 \mathrm{bp}$ ), bioinformatics analyses were performed using standard procedures as described in Pérez-Izquierdo et al. (2017).

For both fungal and bacterial data, per-sample rarefaction curves were calculated to assess sampling completeness, using function rarecurve() in package Vegan v3.5-1 (Oksanen 2015) in $\mathrm{R}$ (version 3.4.3; R Core Team 2016). Based on these, subsequent analyses of diversity and community structure were performed on datasets where samples had been rarefied with the Phyloseq (McMurdie and Holmes 2013) package to achieve equal read numbers according to the minimum number of total reads in any sample $(8,982$ bacteria, 8,005 fungi). Microbial community composition and structure in bulk soil and roots data were further analyzed by using Phyloseq package (McMurdie and Holmes 2013). Alpha diversity was characterized at the OTU level by measuring richness and Shannon index for each sample. Package Metacoder was used for graphical representation of the relative abundances of microbial taxa detected 
in T0 soils and in roots (Foster et al. 2017). Venn diagrams were created on http://bioinformatics.psb.ugent.be/webtools/Venn/.

FUNGuild (Nguyen et al. 2016) was used to classify each OTU into an ecological guild. OTUs identified to a guild with a confidence ranking to highly probable or probable were conserved in our analysis, whereas those ranking to probable or with multiple assignation were unclassified.

Metabolome analyses. Root samples for metabolomic analysis were lyophilized for $24 \mathrm{~h}$ (Alpha 1-2 LI Plus, Christ Martin Osterode am Harz, Germany). Then root metabolome extraction and analyses were carried out as previously described by Tschaplinski et al. (2014). Briefly, between 20 and $100 \mathrm{mg}$ of fresh weight of roots samples was ground to a fine powder in liquid nitrogen, weighed, and then transferred to an acid washed glass scintillation vial containing $2.5 \mathrm{ml}$ of $80 \%$ ethanol. Sorbitol was used before extraction as an internal standard to correct potential extraction efficiency difference and to normalized final concentrations of metabolites in each sample. After overnight extraction and the solvent transferred into another vial, each sample pellet was re-extracted with another $2.5 \mathrm{ml}$ of $80 \%$ ethanol overnight and the supernatant combined with the prior extract. Using a nitrogen stream, $2 \mathrm{ml}$ of this solution was dried and stored at $-80^{\circ} \mathrm{C}$ until analysis. The samples were dissolved in $750 \mu$ of aqueous $80 \%$ ethanol, from which $500 \mu \mathrm{l}$ was dried in a nitrogen stream. Metabolites were trimethylsilyl derivatized and analyzed using GCMS, as previously described (Tschaplinski et al. 2014). The peaks of known metabolites were extracted using a key mass-to-charge $(\mathrm{m} / \mathrm{z})$ ratio and scaled back up to the total ion current using predetermined scaling factors. The scaling factor for sorbitol was used for unidentified metabolites. Unidentified metabolites were denoted by their retention time as well as key $\mathrm{m} / \mathrm{z}$ fragments. Peaks were quantified by area integration and were normalized to the quantity of the internal standard (sorbitol) recovered, accounting for the volume of sample processed, derivatization volume, and injection volume.

Statistical analyses. Statistical analyses and data representations were performed using R software (R Core Team 2016). Averaged relative abundances (RAs) of taxonomic groups were achieved by averaging across all samples from a particular sampling time and soil inoculum. These mean RA values were used to estimate the differential abundance of taxonomic groups depending on soil origin using Student's $t$ test followed by Benjamini-Hochberg false discovery rate (FDR) correction, after verifying normality of data with Shapiro-Wilk test. Differences in RAs of the different fungal guilds between soil inocula were assessed with a Student's $t$ test followed by Bonferroni correction.

Microbial community structures were analyzed using nonmetric multidimensional scaling analysis and permutational multivariate analysis of variance (PERMANOVA) based on Bray-Curtis dissimilarity matrices.

The $P$ values of root metabolite differences were calculated using a one-way ANOVA and post-hoc honest significant difference tests between the means of sets of soil 1 root samples and the means of sets of soil 2 root samples for each sampling time (T1 and T2), with the data expressed as fold changes relative to soil 1 results. Projection to latent structure (PLS) models were used to look for associations between microorganisms and metabolites (mixOmics package, Rohart et al. 2017). To do so, two independent matrices were built: one assembling T1 data and one assembling T2 data. Each matrix contained OTUs and root metabolites showing significant differences in relative abundance between soil 1 and 2, as well as microbial OTUs specifically detected in roots cultivated in soil 1 or soil 2. Each matrix was used independently to PLS graphic representations of metabolite and OTU associations at T1 and T2.

\section{RESULTS}

Soil physico-chemical analysis and climate. Physico-chemical analyses of T0 bulk soils collected under the same poplar tree during early summer 2016 (soil 1) and 2017 (soil 2) were performed to assess potential differences in soil properties over the experiment (Supplementary Table S2). Total organic content, C:N:P stoichiometry, and soil $\mathrm{pH}$ remained relatively stable over the 2 years and were typical of a forest acidic soil with poor phosphorous content and a low cation-exchange capacity (as indicated by CEC values, Supplementary Table S2). By contrast, available amounts of sodium and manganese changed by 3 - and 1.6-fold, respectively. Note that Winter and Spring climates differed between 2016 and 2017, with $2017\left(263 \mathrm{~mm} / 9.7^{\circ} \mathrm{C}\right)$ being unusually dryer than 2016 $\left(544 \mathrm{~mm} / 9.3^{\circ} \mathrm{C}\right)$, despite a similar average temperature (Supplementary Fig. S2).

Microbial sequencing. To characterize the natural variation of soil- and root-associated microbiomes, Illumina MiSeq sequencing of rDNA 16S and ITS amplicons were performed on soils and root DNA. After quality filtering, and chimera and singleton removal, a total of 770,000 fungal reads $(17,500 \pm 4,500$ reads $)$ and 970,000 bacterial reads $(23,000 \pm 8,800$ reads $)$ per sample were kept for further analyses. After taxonomic assignment, elimination of contaminants and rarefactions of data to achieve equal number of reads, 1,521 fungal OTUs (315 \pm 143 per sample) and 6,136 bacterial OTUs $(1,210 \pm 413)$ were identified and analyzed.

Microbial community composition of the initial bulk soils differed. Six fungal phyla were detected in bulk soil T0 in soil 1 and soil 2. Basidiomycota and Zygomycota dominated fungal soil communities at T0 (Fig. 1A) followed by Glomeromycota, Chytridiomycota, and Rozellomycota (Supplementary Table S3). Nine dominant bacterial phyla ( $>1 \%$ relative abundance) were detected in bulk soil T0 in soil 1 and soil 2: Acidobacteria, Proteobacteria, Verrucomicrobia, Bacteroidetes, Chloroflexi, Planctomyces, Actinobacteria, Gemmatimonadetes, and WPS-2 (Fig. 1B, Supplementary Table S3).

Comparison of the structure of fungal and bacterial communities indicated a significant shift in both microbial communities between the two soils (Fig. 2). The soil parameter was responsible for 54 and $62 \%$ of the variability of the bacterial and fungal communities between soil samples (PERMANOVA test, $P<0.05$ ). However, the response of bacterial OTUs was more pronounced than that of fungi as illustrated by alpha-diversity indexes and the relative compositions of the communities. Bacterial, but not fungal, richness and evenness were slightly higher in soil 1 compared with soil 2 (Student's $t$ test, $P<0.05$; Fig. 2C). In addition, although significant variations of relative abundance were measured for both fungi and bacteria at all taxonomic levels, the number of bacterial OTUs that varied between the two soils was higher than that of fungi (Figs. 1 and $2 \mathrm{~A}$ and B). In all, 61 and 58\%, representing 25 and $20 \%$ of total abundance of fungal and bacterial OTUs, respectively, were detected only in one of the two soils. Furthermore, $0.2 \%$ of fungal and $0.8 \%$ of bacterial OTUs ( 2 and 30 , respectively) that were shared between the two soils significantly differed in relative abundance between the two soils (Student's $t$ test, $P<0.05$, Fig. 2A and B). This significant change in community composition did not modify the relative abundance of the different soil fungal trophic guilds: the relative proportion of predicted mycorrhizal fungi, saprotrophs, and potential pathogens was similar in the two soils (data not shown). Instead, we observed a replacement of fungal species within each trophic guild. The ectomycorrhizal fungal community was dominated by Hymenogaster in soil 1, whereas Tuber and Tomentella were prominent in soil 2 (Fig. 1A, Supplementary Table S4). Some bacterial OTUs were specifically detected in a single soil (e.g., 
Bdellovibrio, Acidicapsa, and Terrimonas; Supplementary Table S5), while other OTUs were significantly more abundant in one of the two soils (Student's $t$ test, $P<0.05$; Fig. 2B). For instance, the relative abundance of Candidatus Udaeobacter was 3.5-fold higher in bulk soil T0 collected in soil 1 compared with soil 2, while
Bryobacter and Acidothermus were more abundant in soil 2 (Student's $t$ test, $P<0.05$; Fig. 1B; Supplementary Table S6).

Populus root microbiome structure and composition varied depending on bulk soil inoculum. To test whether natural variations in the composition of soilborne microorganisms may impact
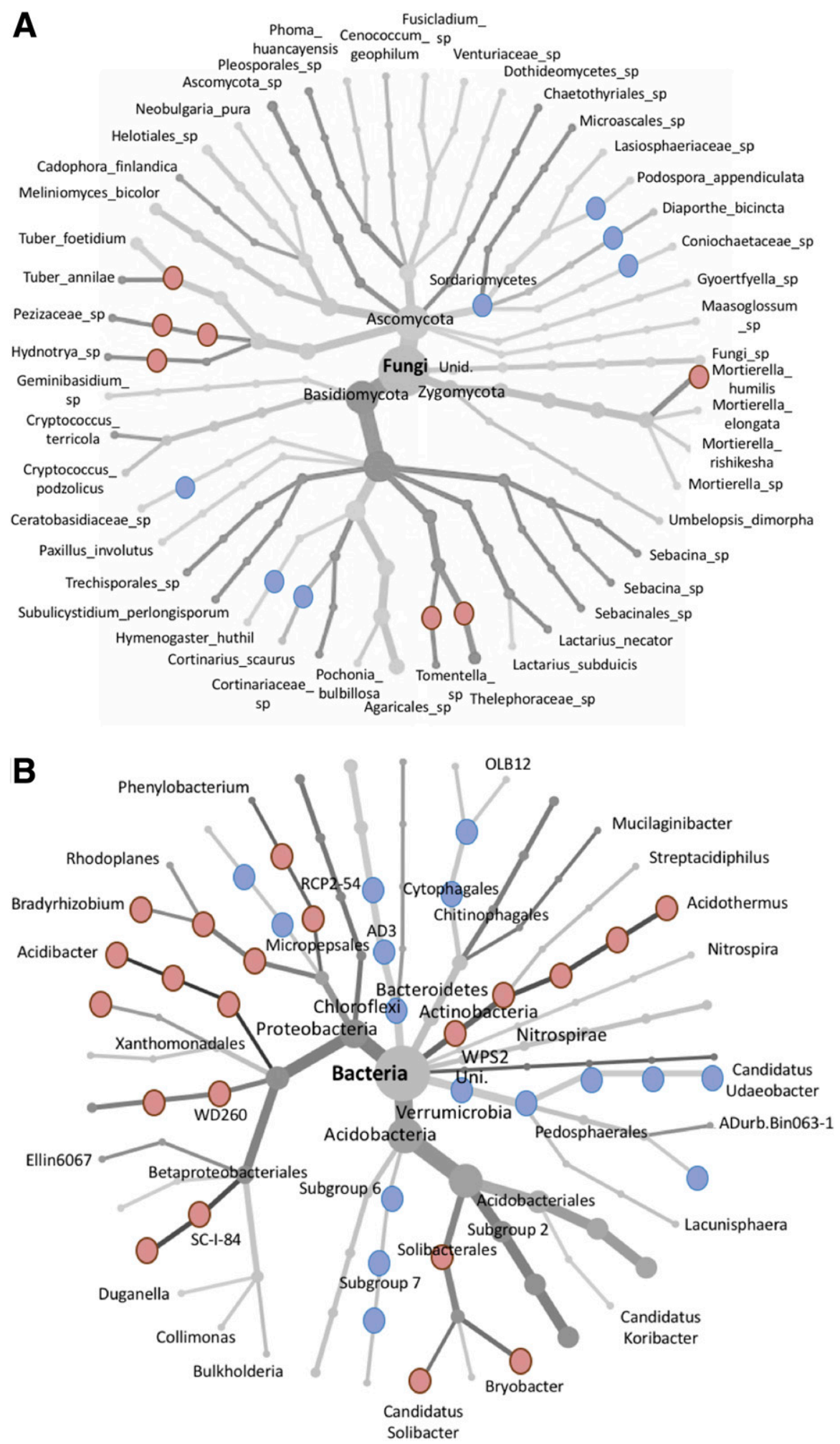

Fig. 1. Taxonomic representation of the most abundant $\mathbf{A}$, fungal and $\mathbf{B}$, bacterial communities $(>0.1 \%$ in total relative abundance) detected in bulk soil T0. The thickness of tree branches represents the value of $\log _{2}$ ratio between soil 1 and soil 2 at each taxonomic rank. The thicker the line, the more important the value. Blue circles represent microbial taxonomic rank significantly more abundant in soil 1, whereas red circles represent microbial taxonomic rank significantly more abundant in soil 2 (Student's $t$ test, $P<0.05$ ). 

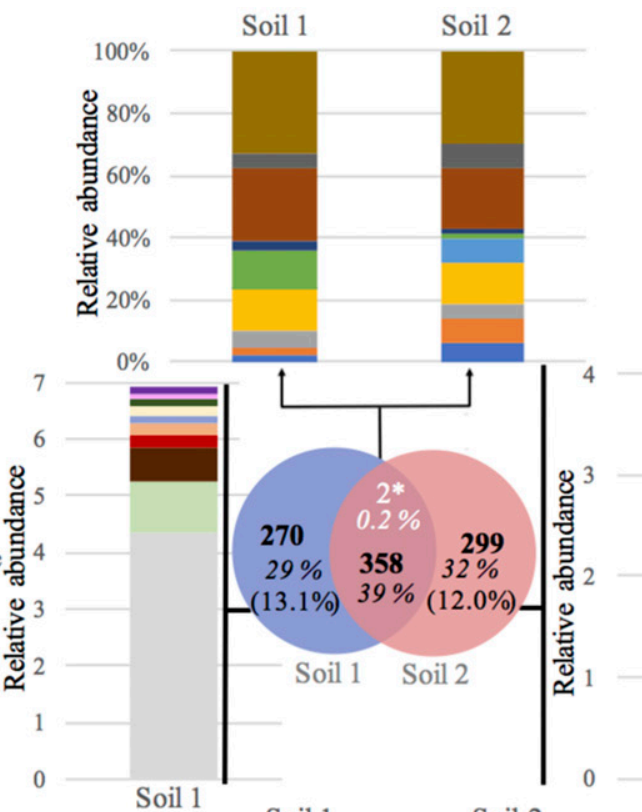

- Other

-UG of Thelephoraceae

- UG

- Umbelopsis

- Tuber

- Sebacina

Mortierella

- Meliniomyces

- Lactarius

- Hydnotrya

B

-UG of Helvellaceae
" UG of Glomeraceae
- Cunninghamella
Pseudeurotium
" UG of Herpotrichiellacea
" Peziza
- Entorrhiza
-UG of Coniochaetaceae
" Podospora
" Hymenogaster

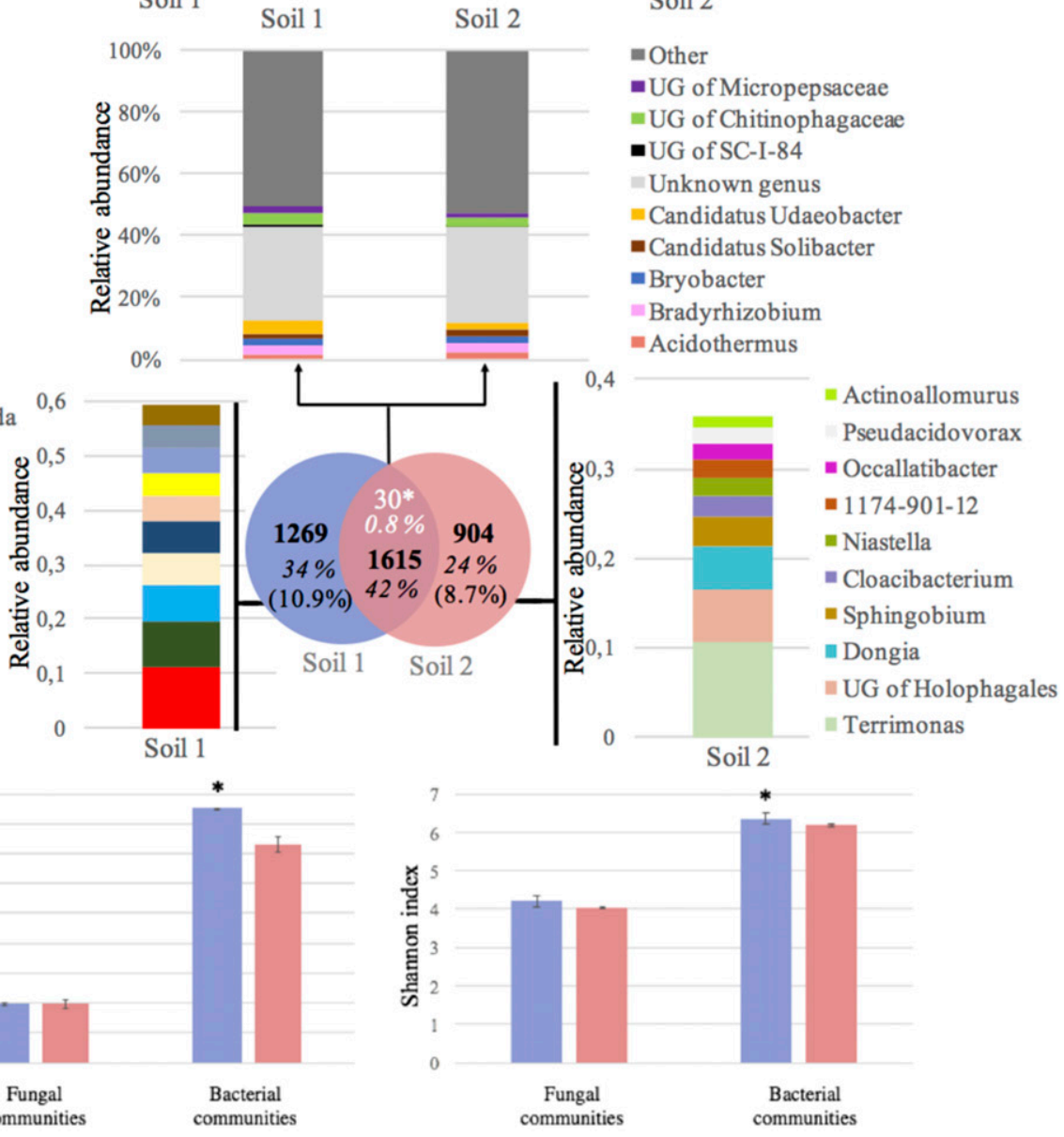

Fig. 2. Differences in the composition and diversity of fungal and bacterial communities between To bulk soils. Venn diagrams indicate the number of the A, fungal and B, bacterial operational taxonomic units (OTUs) detected only in one soil of the experiment or retrieved in both soils. The number in bold represents the number of OTUs detected only in one soil of the experiment or retrieved in both soils. This value is converted in percentage in italic and in relative abundance of total OTUs in brackets. The number in white followed by an asterisk represents the number of OTUs whose relative abundance is significantly different between the two soils $\left({ }^{*}=P<0.05\right.$, Student's $t$ test). This value is converted in percentage in italic. C, Compared alpha diversity of the fungal and bacterial communities from the bulk soil T0 collected in soil 1 and in Soil 2 (richness and Shannon index). Diversity indices are given as means \pm standard error. The asterisks denote significant difference in each alpha-diversity measure between soil 1 and soil $2\left({ }^{*}=P<0.05\right.$, Student's $t$ test; $n=3)$. 
the root microbiome, we characterized bacterial and fungal communities in roots of poplar cuttings grown in greenhouse in soil 1 and soil 2.

Overall, six fungal phyla and 13 dominant $(>1 \%$ relative abundance) bacterial phyla were detected in roots of cuttings grown in soil 1 and soil 2. Like in soil, Ascomycota, Basidiomycota, and Zygomycota dominated the root communities, while Proteobacteria, Actinobacteria, Patescibacteria, Acidobacteria, and Verrucomicrobia were the most abundant bacterial phyla (Supplementary Fig. S3). Fungi identified in the roots mainly belonged to the trophic groups of ectomycorrhizal fungi $(28.2 \pm 3.8 \%)$, fungal endophytes $(12.3 \pm 1.5 \%)$, and saprotrophic fungi $(5.5 \pm 1.0 \%)$.

The structures of fungal and bacterial communities colonizing roots clearly differed depending on the soil for both sampling times, as illustrated by nonmetric multidimensional scaling analyses (Fig. $3 \mathrm{~A}$ and $\mathrm{B})$. The soil parameter was responsible for $31 \%$ of the variability of the bacterial and fungal communities between root samples according to the PERMANOVA test, while the stage of colonization (T1 versus T2) explained 16 and $17 \%$ of the variability, respectively. By contrast, no significant difference was observed in microbial community structure of the bulk soils in the pots along the different sampling times of the experiment, suggesting that neither the greenhouse parameters (e.g., temperature and humidity) nor the tree seedlings impacted the soil microbial community structure (Fig. 3A and B).

In Populus roots harvested at T1, 68\%, representing 22.7 and $22.6 \%$ of total abundance of fungal and bacterial OTUs, respectively, were detected only in the roots collected in one of the two soils. Furthermore, $0.5 \%$ of fungal and $0.03 \%$ of bacterial OTUs (3 and 1 , respectively) that were shared between the two soils significantly differed in relative abundance (Student's $t$ test, $P<0.05$, Fig. 3C and D). In Populus roots harvested at T2, 67 and 66\%, representing 19 and $14 \%$ of total abundance of fungal and bacterial OTUs, respectively, were detected only in the roots collected in one of the two soils (Supplementary Table S7 and S8). Furthermore, $0.4 \%$ of fungal and $0.2 \%$ of bacterial OTUs ( 2 and 4 , respectively) that were shared between roots grown in the two soils significantly differed in relative abundance (Student's $t$ test, $P<0.05$, Fig. 3C and D). These changes in root community composition associated with soil variation resulted in a modification of the relative abundance of fungal trophic guilds, particularly at T1. Ectomycorrhizal fungi tended to be more abundant in roots grown in soil 2 than in soil 1, while endophytes, plant pathogens, and arbuscular mycorrhizal fungi tended to be more abundant in roots grown in soil 1 than in soil 2 (Student's $t$ test, $P<0.05$; Fig. 4). At T2, the relative abundance of fungal endophytes was significantly higher in soil 1
A

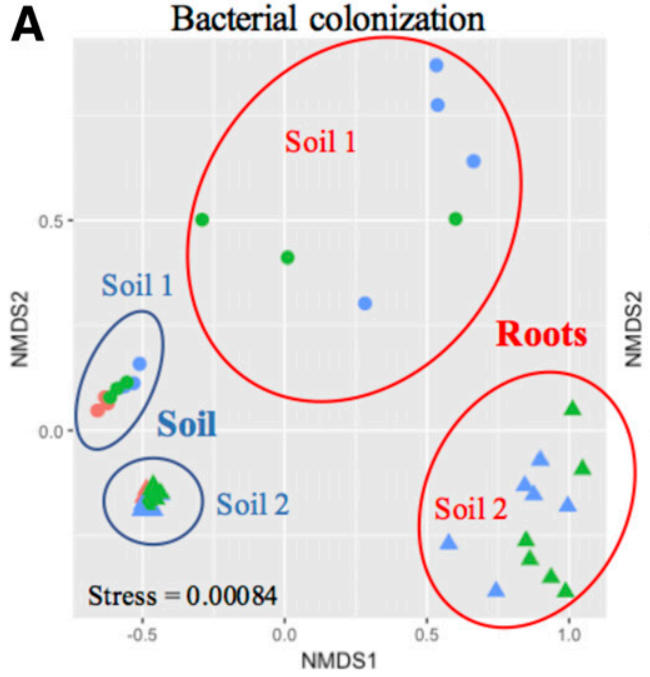

C

Fungal OTUs in roots (T1)

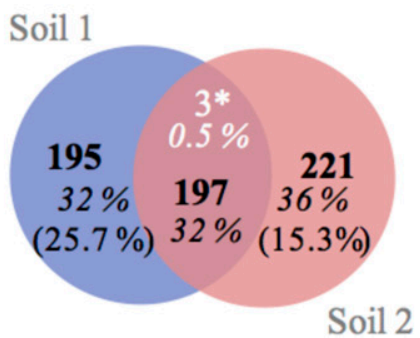

Fungal OTUs in roots (T2)

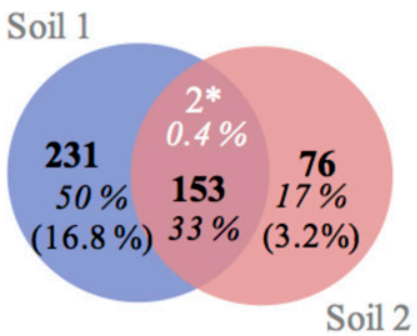

\section{Fungal colonization}
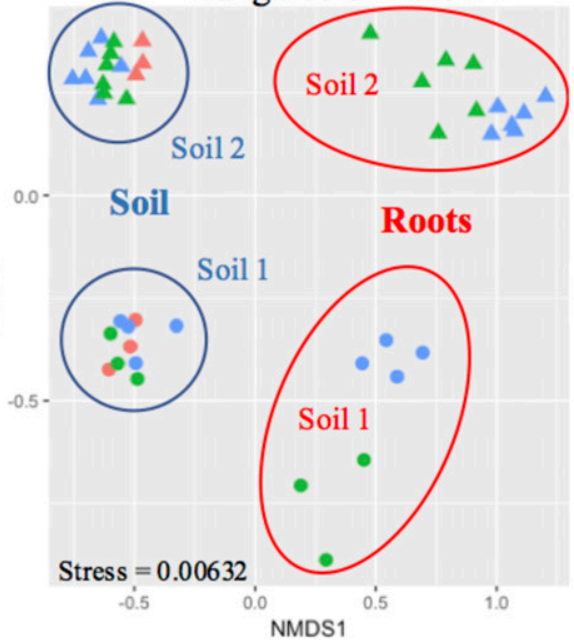

Bacterial OTUs in roots (T1)

Soil 1

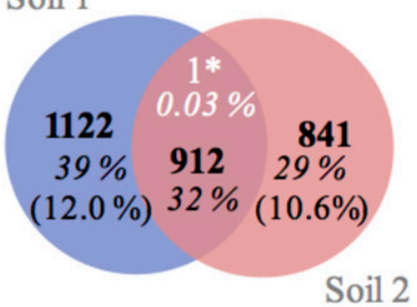

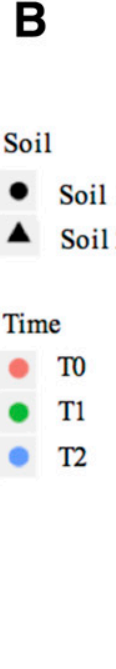

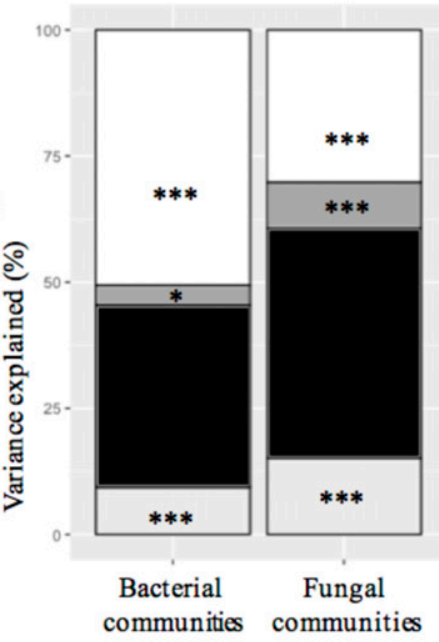

Fig. 3. Differences in the structure and composition of root fungal and bacterial communities of cuttings grown in soil 1 and soil 2 . A, Nonmetric multidimensional scaling (NMDS) analysis ordinations of fungal and bacterial communities across compartments (soil and roots), sampling time (T0, red; T1, green; and T2, blue), and soil origin (soil 1, circles; soil 2, triangles). B, Variance explanation based on permutational multivariate analysis using Euclidean dissimilarity matrix for bacterial and fungal communities (white, compartment; gray, time; black, unexplained; light gray, year; ${ }^{*}, P<0.05$; and $\left.{ }^{* \star *}, P<0.001\right)$. C, Venn diagrams of the fungal and bacterial operational taxonomic units (OTUs) detected in roots grown in the two soils. The number in bold represents the number of OTUs detected in roots only in one soil condition or retrieved in both soil conditions. This value is converted in percentage in italic and in relative abundance of total OTUs in brackets. The number in white followed by an asterisk represents the number of OTUs whose relative abundance is significantly different between the two soil conditions $\left(^{*}=P<0.05\right.$, Student's $t$ test). This value is converted in percentage in italic. 
roots compared with soil 2 roots. Indeed, we observed that the relative abundance of the fungal endophytes Mortierella and Phialocephala was, respectively, 23 and 25 times higher in soil 1 roots compared with soil 2 roots. While the relative abundance of the other fungal trophic guilds was maintained over the two conditions, we observed that the saprotrophes Phaemollisia and Ramicandelaber were significantly more abundant in soil 1 roots, whereas the ectomycorrhizal fungus belonging to the family Thelephoraceae were 6.5 times higher in roots of Populus harvested in soil 2 (Student's $t$ test, $P<0.05$, Supplementary Table S9).

Similarly, some bacterial OTUs were specifically detected in roots grown in one of the two soils (e.g., Pedobacter, Amycolatopsis, Allorhizobium-Neorhizobium-Pararhizobium-Rhizobium, and Lacunisphaera; Supplementary Table S8), while others were significantly more abundant in roots grown in one of the two soils. At $\mathrm{T} 1$, the relative abundance of bacteria belonging to Gammaproteobacteria Incartae Sedis, Coxiellales, and Acetobacterales were three times higher in roots collected in soil 2, while Xanthomonadales relative abundance was significantly enriched in roots collected in soil 1 (Student's $t$ test, $P<0.05$, Supplementary Table S6). At the genus level, Rhodanobacter relative abundance was higher in roots of soil 1 , whereas relative abundance of Acidibacter, Coxiella, and Phenylobacterium were significantly enriched in roots collected in soil 2 (Student's $t$ test, $P<0.05$, Supplementary Table S9). At T2, significant differences in relative abundance were only observed at the bacterial order level. Xanthomonadales, Saccharimonadales, and Catenulisporales were significantly more abundant in soil 1 roots, while Ktedobacterales, Chitinophagales, Pedosphaerales, Rhizobiales, and Sphingobacteriales were significantly more abundant in soil 2 roots (Student's $t$ test, $P<0.05$, Supplementary Table S9).

Root metabolome varies according to soil inoculum and correlates with microbiome composition. Since the composition of the root-associated microbiome could impact by the metabolism of the host plant (Berg and Smalla 2009), we characterized by GCMS the root metabolome of poplar cuttings grown for 10 days and 6.5 weeks in soils of the poplar plantation sampled on 2016 (soil 1) and 2017 (soil 2). A total of 90 metabolites were quantified in roots
A

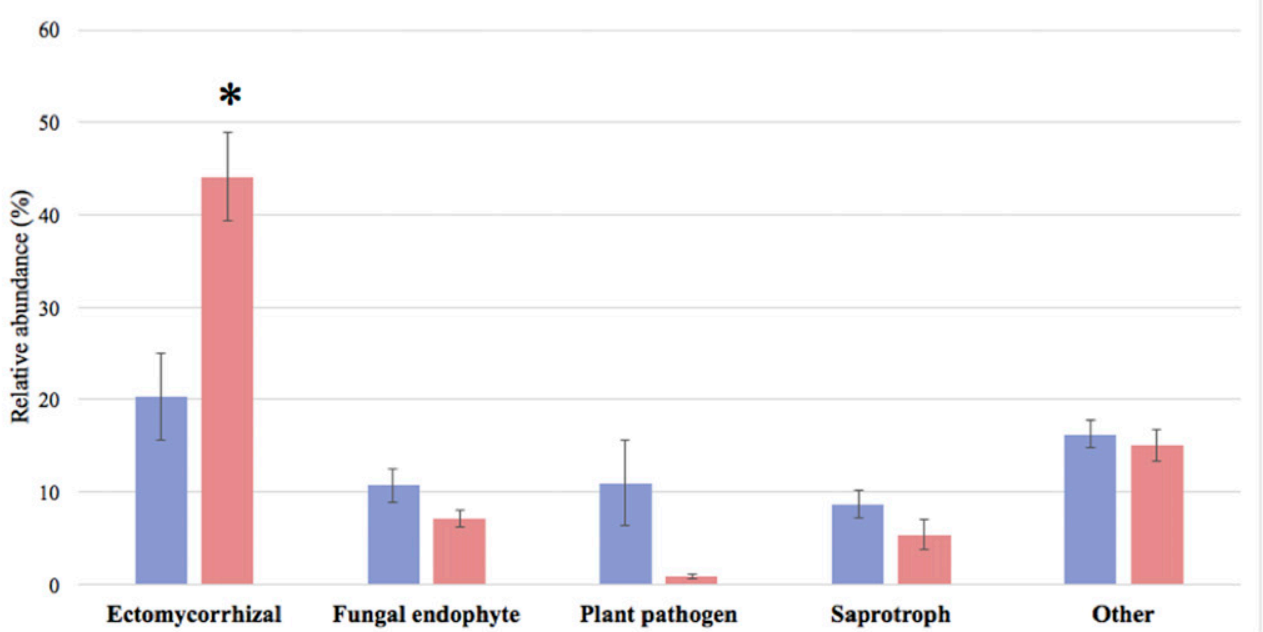

$\mathrm{T} 1$

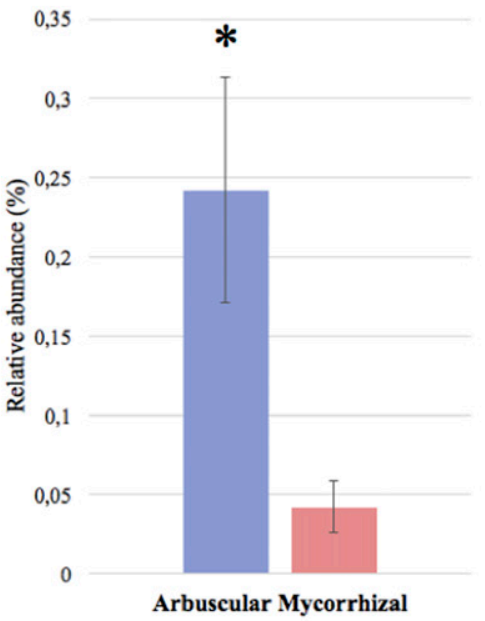

B

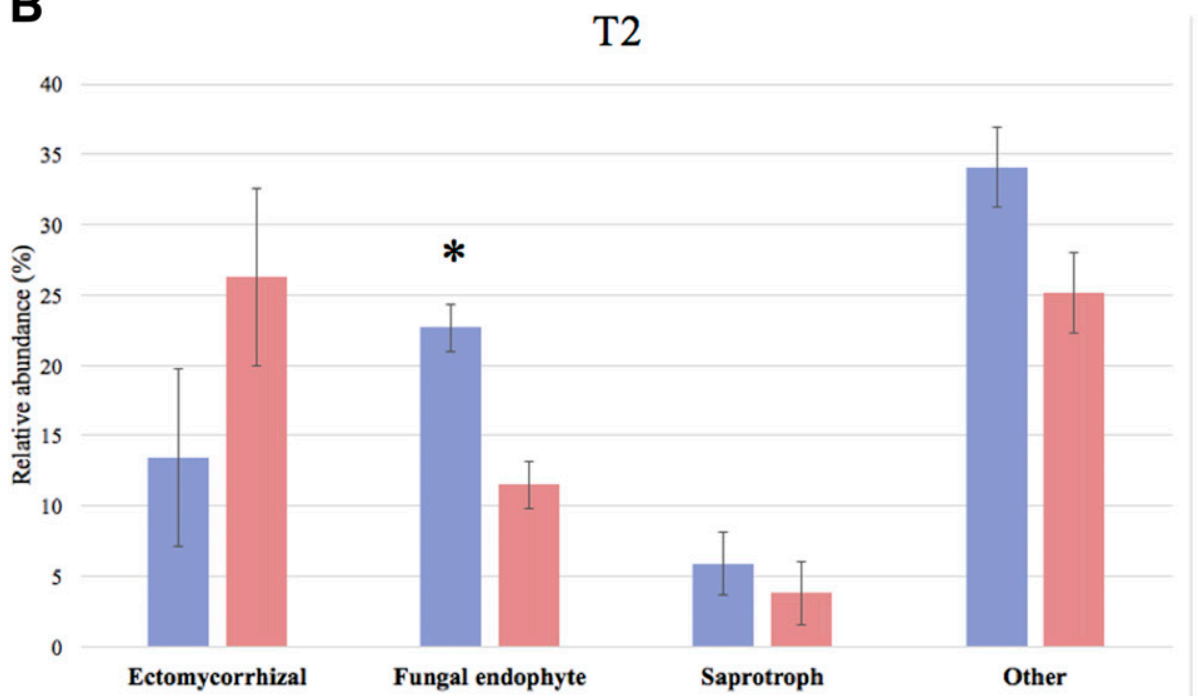

$\mathrm{T} 2$

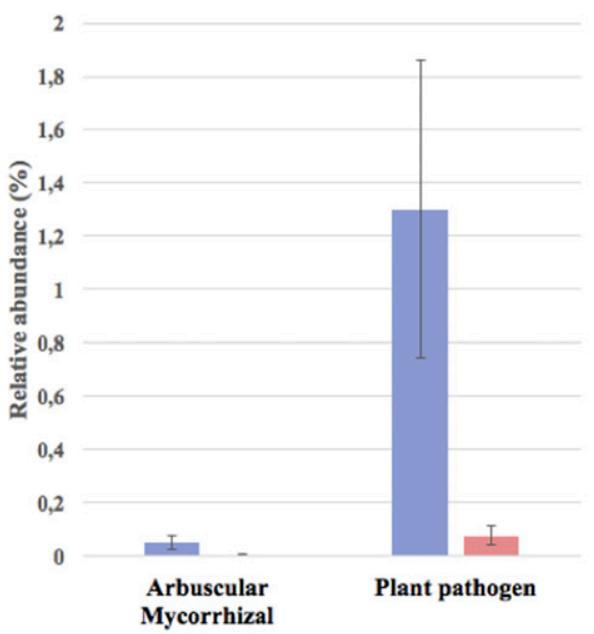

Fig. 4. Relative abundance of fungal functional guilds of OTUs detected in roots of Populus tremula $\times$ alba harvested at A, T1 and B, T2 grown in soil 1 (blue) and soil 2 (red). The asterisks indicate significant differences in relative abundance of fungal guilds between soil 1 roots and soil 2 roots $\left(^{*}=P<0.05 ;\right.$ Student's $t$ test $)$. 
harvested at T1 and T2. Some of these metabolites are known to be only produced by Populus while others can also be of microbial origin (Supplementary Table S10). Thirty-four of the detected metabolites were involved in primary metabolism, while 38 were linked to secondary metabolism. In addition, 18 detected metabolites corresponded to unidentified compounds. The main primary metabolites ( $>1 \%$ of the total metabolites amount) were sucrose $(30.7 \%)$, malic acid $(9.7 \%)$, glucose $(8.1 \%)$ and fructose $(3.7 \%)$, palmitic acid $(3.3 \%)$, and phosphate and galactose (1.3\%), while secondary metabolites were dominated by salicylic acid derivatives ( $\alpha$-salicyloylsalicin, 14.1\%; salicin, 6.7\%; and tremuloidin, 3.9\%), as well as $\beta$-sitosterol (2.1\%) and catechin (1.7\%) (Supplementary Table S10).

Differential root colonization by soil fungal and bacterial communities was correlated with changes in 10 to $20 \%$ of root metabolites collected from soil 1 and soil 2 . At T1, only seven metabolites differed significantly between soil 1 and soil 2 , out of the 76 compounds quantified in roots extracts. Alanine, salicylic acid, and an unidentified compound (10.68 min, m/z 217391411 ) significantly increased with a fold change of $9,2.5$, and 2 , respectively, in roots collected from soil 1 compared with soil 2, whereas mannitol, glycerol (16.11 min, m/z 297), guaiacyl lignan, and another unidentified compound (14.09 min, m/z 375292 217) significantly increased with a fold change of $13,8,2$, and 3 , respectively, soil 2 roots compared with soil 1 roots (one-way ANOVA, $P<0.05$; Table 1).

At T2, 18 metabolites differed between soil 1 and soil 2 roots, out of the 84 compounds quantified in root extracts. Alanine was the most responsive metabolite, exhibiting a 20 -fold increase in concentration in soil 1 roots compared with soil 2 roots, followed by oxalomalic acid (eightfold increase) (one-way ANOVA, $P<0.05$; Table 1). The concentrations of some metabolites involved in carbon metabolism, such as fructose and glucose, also varied (oneway ANOVA, $P<0.05$; Table 1 ).

A PLS combining amplicon sequencing and metabolite data was conducted to investigate the existence of potential associations between changes in abundance in the roots of microbial OTUs and metabolites (Fig. 5).

At T1, the enrichment in the bacterial genera Cytophaga, Acidibacter, Candidatus Ovatusbacter, Coxiella, and Silvanigrella,

TABLE 1

List of metabolites detected in roots of Populus tremula $\times$ alba harvested after 10 days (T1) and 6.5 weeks (T2) of growth for which a significant difference of concentration has been measured between soil 1 and soil $2\left({ }^{*}=P<0.05\right.$, one-way analysis of variance)

\begin{tabular}{|c|c|c|c|c|c|}
\hline \multirow[b]{2}{*}{ Metabolite (RT-m/z) } & \multirow[b]{2}{*}{$\begin{array}{c}\text { Plant } \\
\text { metabolite }\end{array}$} & \multirow[b]{2}{*}{$\begin{array}{l}\text { Bacterial or fungal } \\
\text { metabolite }\end{array}$} & \multicolumn{2}{|c|}{$\begin{array}{c}\text { Populus roots collected in soil } 1 \\
\text { versus soil } 2\end{array}$} & \multirow{2}{*}{$\begin{array}{c}\text { Root } \\
\text { metabolites } \\
\text { of } P \text {. tremula } \times \\
\text { alba }(\%)^{\mathrm{b}}\end{array}$} \\
\hline & & & $\begin{array}{l}10 \text { days of growth } \\
(\mathrm{T} 1)^{\mathrm{a}}\end{array}$ & $\begin{array}{l}6.5 \text { weeks of growth } \\
(\mathrm{T} 2)^{\mathrm{a}}\end{array}$ & \\
\hline Sucrose ${ }^{c}$ & $x$ & $x$ & 0.61 & $0.40^{*}$ & 30.72 \\
\hline Malic acid ${ }^{c}$ & $\mathrm{x}$ & $x$ & 1.77 & $0.59^{\star}$ & 9.74 \\
\hline Glucose $^{c}$ & $x$ & $x$ & 4.87 & $3.13^{*}$ & 8.11 \\
\hline Catechin $^{d}$ & $x$ & & 1.00 & $0.42^{*}$ & 1.68 \\
\hline 7.691691017568 & & $?$ & ND & $3.16^{*}$ & 1.65 \\
\hline Mannitol $^{\mathrm{C}}$ & & $x$ & $0.08^{*}$ & 0.79 & 0.65 \\
\hline Salicylic acid $^{d}$ & $\mathrm{x}$ & $\mathrm{x}$ & $2.55^{\star}$ & 0.48 & 0.51 \\
\hline Glycerol $^{\mathrm{C}}$ & $x$ & $x$ & $0.13^{*}$ & 0.46 & 0.50 \\
\hline Oxalomalic acid ${ }^{c}$ & $x$ & $x$ & 54.78 & $7.63^{*}$ & 0.08 \\
\hline 10.68217391411 & & $?$ & $2.15^{\star}$ & $4.11^{*}$ & 0.06 \\
\hline Xylono-1,4-lactone $^{d}$ & $x$ & & 2.72 & $2.09^{*}$ & 0.04 \\
\hline Maleic acid $^{c}$ & $x$ & $x$ & 1.09 & $0.28^{*}$ & 0.032 \\
\hline 14.09375292217 & & $?$ & $0.34^{*}$ & ND & 0.030 \\
\hline 16.11 guaiacyl lignan ${ }^{d}$ & $x$ & & $0.45^{\star}$ & 0.85 & 0.028 \\
\hline Phluoroglucinol $^{d}$ & $x$ & $\mathrm{x}$ & 4.84 & $4.84^{\star}$ & 0.021 \\
\hline Erythronic acid $^{\mathrm{C}}$ & $x$ & & 0.94 & $0.51^{*}$ & 0.014 \\
\hline $\begin{array}{l}\text { 6-Hydroxy-2-cyclohexenone-1- } \\
\text { carboxylic acid }^{\mathrm{d}}\end{array}$ & $x$ & $x$ & 0.78 & $0.25^{\star}$ & 0.013 \\
\hline
\end{tabular}

a Values indicate fold changes between soil 1 and soil 2.

b The last column indicates the relative abundance of each metabolite in the total root metabolome of Populus tremula $\times$ alba seedlings.

c Metabolites involved in primary metabolisms.

d Metabolites involved in secondary metabolisms. 
the ectomycorrhizal fungi Tuber and Hydnotrya in soil 2 roots was associated with an accumulation of glycerol and mannitol in roots. In contrast, the enrichment of the bacterial genus Methylophilus, the fungal endophytes Mortierella and Fusarium, and the ectomycorrhizal fungus Paxillus in soil 1 roots was associated with the accumulation of salicylic acid (Fig. 5A).

At $\mathrm{T} 2$, associations between several microorganisms were evident (Fig. 5B). For instance, the associations of bacterial genera
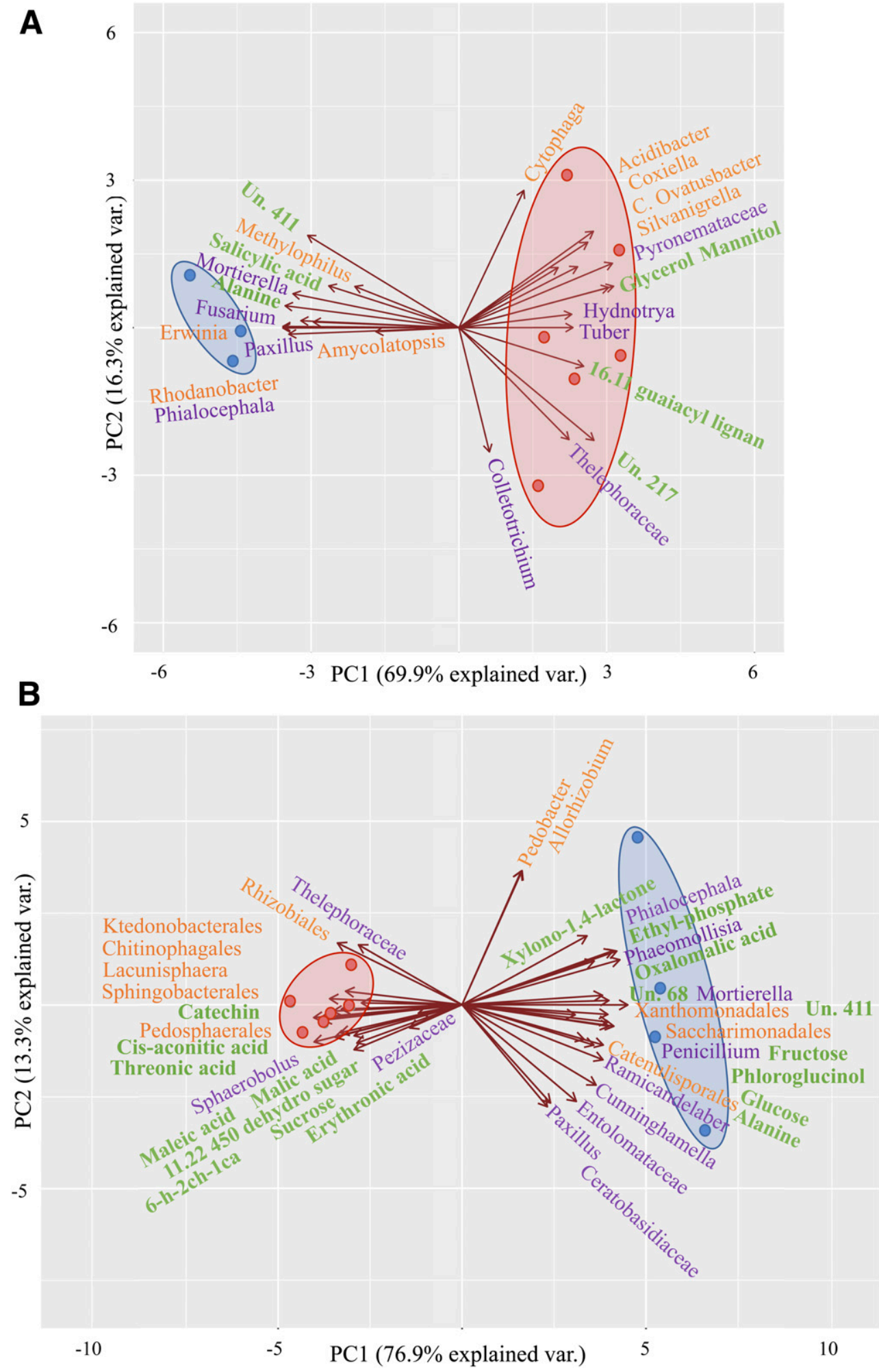

Fig. 5. Projection to latent structures of the dominant root microbial communities and root metabolites significantly varying between soil 1 (red) and soil 2 (blue) conditions at $\mathbf{A}, \mathrm{T} 1$ and $\mathbf{B}, \mathrm{T} 2$. Bacterial $(>0.1 \%$ relative abundance), fungal $(>0.5 \%)$ taxa, and metabolites are represented in orange, purple, and green, respectively. Un. $411=$ unidentified $10.68 \mathrm{~m} / \mathrm{z}, 217391411 ;$ Un. $217=$ unidentified 14.09 m/z, $375292217 ;$ Un. $68=$ unidentified $7.69 \mathrm{~m} / \mathrm{z}$, 16910175 68; and 6-h-2ch-1ca = 6-hydroxy-2-cyclohexenone-1-carboxylic acid. 
Pedobacter and Allorhizobium or the ectomycorrhizal fungi of the family Telephoraceae and bacterial OTU from the order Rhizobiales were tightly linked. Associations between the presence of microorganisms and the accumulation of metabolites were also revealed. The enrichment of the dark septate endophyte Phialocephala and, the saprotrophic fungus Phaomollisia in soil 2 roots was associated with the accumulation of primary metabolites oxalomalic acid and xylono-1.4-lactone. The presence and/or enrichment of three bacterial orders (Xanthomonadales, Catenulisporales, and Saccharimonadales) three saprotrophic fungi (e.g., Penicillium and Cunninghamella), the ectomycorrhizal fungus Paxillus was associated with increased levels of primary metabolites, including fructose, glucose, and alanine, and the secondary metabolite, phloroglucinol. Conversely, in soil 1 roots, the presence of five bacterial orders (e.g., Pedosphaerales and Sphingobacterales), the saprotrophic fungus, Sphaerobolus, and members of the Pezizaceae were associated with the accumulation of several primary metabolites (e.g., malic acid and sucrose) and the secondary metabolite, catechin.

\section{DISCUSSION}

The composition of the root microbiome and the host metabolism are tightly interrelated: the type and level of carbon and nitrogen compounds accumulating and released by roots strikingly influence the nature and abundance of soilborne microorganisms colonizing the rhizosphere and root tissues (Berg and Smalla 2009; Jacoby et al. 2017). Abiotic stresses experienced by trees lead to major physiological alterations triggering dramatic shifts in root microbial communities (Timm et al. 2018). Conversely, the composition of the microbial communities colonizing roots can modulate tree nutrition and their sensitivity to diseases and stresses as microorganisms can differ in their abilities to capture nutrients or restrict pathogen colonization (Chaparro et al. 2012; DeAngelis et al. 2009). However, a high level of functional redundancy exists among root-colonizing microorganisms and the replacement of a species by another can be functionally neutral (Colin et al. 2017). Soil is the major reservoir of microorganisms from which plants draw their rhizospheric and endophytic microbiomes (Edwards et al. 2015; Mercado-Blanco et al. 2018). This pool of soil microorganisms is likely to greatly vary locally over time due to environmental changes, such as drought, flooding, or heat waves (Brockett et al. 2012). Here, we asked whether natural variations in the soil microbial reservoir influence the root-associated microbiome of poplar and its metabolome, or whether such variations are buffered by functional redundancies in microbial communities. We observed that only $\sim 40$ and $30 \%$ of the fungal and bacterial OTUs, respectively, were conserved in the soil and roots over the 2 years of the experiment. This important turnover of microbial taxa was accompanied by changes in the relative proportion of fungal guilds, i.e., symbionts, pathogens, and endophytes, colonizing roots. Alterations in microbial communities were correlated to a shift in the level of $10 \%$ of the root metabolites, including carbohydrates, amino acids, and secondary metabolites.

Changes in bulk soil microbiome are accompanied by a change in the composition and structure of the root-associated microbiome. The soil microbiome of the poplar plantation was typical of a forest soil with low pH (Lladó et al. 2017; Uroz et al. 2016): Acidobacteria and Proteobacteria dominated the bacterial communities, while fungal communities were mainly made of a mix of ectomycorrhizal fungi (e.g., Tuber, Hymenogaster, and Hydnotrya) and saprophytes (e.g., Podospora) as previously observed in soils of other Populus genotype plantations (Beckers et al. 2017; Bonito et al. 2014). However, soil microbiome composition and structure were significantly different between the 2 years of the experiment with more than half of fungal and bacterial OTUs being replaced from 1 year to the other. Many factors can be responsible for this difference; local heterogeneity in soil microbial community, disturbing effect of the first sampling, and climate differences between the 2 years of sampling (winter drought in 2017). In any cases, the changes in the bulk soil communities were large enough to result in an alteration of the root microbiome.

Root bacterial and fungal communities were similar to those previously described in other Populus genotypes (Beckers et al. 2017; Bonito et al. 2016, 2019; Durand et al. 2017; Shakya et al. 2013): bacteria of the genera Actinospica (Actinobacteria), Mucilaginibacter (Sphingobacteria), and Bradyrhizobium (Rhizobiales), the ectomycorrhizal fungi, Paxillus, and members of Thelephoraceae, and the endophytes Mortierella, dominated in the microbial communities.

As observed in soil, the composition and structure of root microbial communities varied depending on the soil inoculum. Some bacterial and fungal genera shifted in relative abundance between roots grown in soil 1 and soil 2, but we also observed that 17 to $50 \%$ of microbial OTUs were soil specific. This is in accordance with the fact that soil microbiome is a more important driver of bacterial and fungal community assemblage in Populus and other trees than genetic factors (Bonito et al. 2014; Uroz et al. 2016; Veach et al. 2019). However, this contrasts with the hypothesis, forwarded from other studies on other plant types, that roots exert a recruitment effect on microbial consortia independent of the microbiome source (Edwards et al. 2015; Pérez-Jaramillo et al. 2016). Thus, the relative importance of soil microbiome versus plant factors likely varies depending on plant type and species.

While the relative abundance of particular taxa of ectomycorrhizal fungi (e.g., Tuber, Thelephoraceae, and Hydnotrya), endophytes, and saprotrophes (e.g., Mortierella) changed in soil, the relative abundance of each fungal trophic guild was maintained in soil over the 2 years. By contrast, in the Populus roots, changes in the relative abundance of specific taxa (e.g., Tuber, Thelephoraceae and Hydnotrya at T1, and Phialocephala and Mortierella at T2) was accompanied by change in the relative abundance of trophic guilds. Similarly, the inoculation of Populus roots with the endophyte Mortierella led to a change in the entire fungal community colonizing the root system (Liao et al. 2019). Changes in the relative contribution of trophic guilds also take place over development stages in poplars and other trees (Gehring et al. 2006; Hacquard and Schadt 2015). Altogether, these findings suggest that the balance between ectomycorrhizal fungi, endophytes, and saprophytes, is unstable and not entirely controlled by rootborne factors. It is likely affected by the composition of the soil microorganism pool and environmental fluctuations. Since these different types of fungi have different roles in terms of nutrition and protection against stresses (Baum et al. 2018; Van Der Heijden et al. 2008), one could expect that such changes would impact Populus tree nutrition and physiology or possibly limit stress resistance of trees to biotic and abiotic stress. For instance, the endophytic Mortierella can stimulate the growth of Populus and modify the activity of ectomycorrhizal fungi, but also other saprotrophic fungi and fungal endophytes (Bonito et al. 2016; Liao et al. 2019).

Changes in the composition and structure of the rootassociated microbiome are accompanied by a change in the root metabolome. In accordance with this hypothesis, the changes in the root microbiome were concomitant with a modification of $10 \%$ of the measured root metabolites. Changes were mainly observed in cuttings after 6.5 weeks of growth in plantation soil. Major differentially accumulated metabolites were related to primary carbon metabolism (15\%). Of note, a number of the responsive 
compounds are those that are often found in tree root exudates (e.g., malate, maleate, and alanine) and/or involved in nutrient fluxes between ectomycorrhizal fungi and their host roots. The observed decrease in sucrose level was correlated with an increased level of fructose and glucose as observed in PisolithusEucalyptus ectomycorrhizae (Martin et al. 1998). Concomitantly, the level of alanine involved in nitrogen transfer from Paxillus to the roots (Chalot et al. 1995) significantly increased in roots. Similarly, the accumulation of the storage sugar mannitol correlated with the presence of the ectomycorrhizal Hydnotrya and Tuber. Ectomycorrhizal fungi produce mannitol which serves as a storage compound but also as an osmo-protectant to preserve fungi of abiotic stresses such as drought (Solomon et al. 2007). Altogether, these results suggest that the replacement of some specific ectomycorrhizal fungal species by others within the microbiome could significantly affect nutrient fluxes and metabolism of Populus roots, as previously suggested by functional comparison of ectomycorrhiza of different species (Mello and Balestrini 2018). Further in situ functional analyses are needed to characterize these relationships.

It is also possible that modification of the colonization by fungal endophytes (e.g., Phialocephala) led to the alteration of the primary metabolism in the roots. In raygrass, fungal endophytes colonization induced important changes in the host cells, notably in the expression of genes encoding for proteins involved in the tricarboxylic acid cycle (TCA) cycle (Dupont et al. 2015). Organic acids that varied in concentration between poplar roots grown in soil 1 and soil 2 also participate in the TCA cycle, in addition to be found in root exudates. This shift in the concentration of TCA cycle metabolites was positively or negatively correlated with significant shifts of a part of the fungal root microbiome.

Secondary metabolism was also affected over the 2 years, although to a lesser extent than primary metabolism. The accumulation of several secondary metabolites, such as salicylic acid (T1) and phloroglucinol (T2), was associated with an increased presence of some microorganisms. For instance, bacterial OTUs from the genus Methylophilus, the fungal endophytes Mortierella and the saprotrophes Penicillium tended to be more abundant at higher levels of salicylic acid at $\mathrm{T} 1$. Increases in the relative abundance of the latter two fungi were also associated with increased level of phloroglucinol at T2. Phloroglucinol is involved in plant defense against soilborne pathogenic microbes, in addition to its role as growth regulator (Haas and Keel 2003). Salicylic acid modulates the colonization of the root by specific bacterial taxa in Arabidopsis (Lebeis et al. 2015) and by pathogenic fungi (Dieryckx et al. 2015). Its impact on the fungal symbiont is currently poorly known, but it is likely that salicylic acid affects fungal symbiont root colonization (Basso et al. 2020). At the same time, some microorganisms trigger salicylic acid production as part of a defense response (Liao et al. 2019; Martínez-Medina et al. 2017). Whether specific microorganisms have induced the accumulation of these secondary metabolites or whether the secondary metabolites have promoted colonization by specific microorganisms will require further study.

Conclusion. In conclusion, the root microbiome of Populus and its metabolome are strongly influenced by variations in the composition of the surrounding bulk soil microbiome. On one hand, as such variations are expected to be amplified in the future by the frequency of extreme climatic events (e.g., winter and summer droughts, heat waves, etc.), it can be predicted from our results that these events will indirectly affect Populus trees through the recruitment of their root microbiome. On the other hand, one could imagine taking advantage of such process for engineering soil microbiomes in order to improve the resistance of Populus to environmental stresses. Future works are needed to assess if such applications are feasible.

\section{ACKNOWLEDGMENTS}

We thank Lucas Auer (INRAE Nancy) for his help in implementing PLS analyses; and Patrice Vion, Yoann Guignet, and Mehdi Maaroufi (INRAE Nancy) for their help in growing, maintaining, and harvesting poplars.

\section{LITERATURE CITED}

Afgan, E., Baker, D., Van den Beek, M., Blankenberg, D., Bouvier, D., Čech, M., et al. 2016. The Galaxy platform for accessible, reproducible and collaborative biomedical analyses: 2016 update. Nucleic Acids Res.: W3-W10.

Basso, V., Kohler, A., Miyauchi, S., Singan, V., Guinet, F., Šimura, J., Novák, O., Barry, K. W., Amirebrahimi, M., Block, J., Daguerre, Y., Na, H., Grigoriev, I. V., Martin, F., and Veneault-Fourrey, C. 2020. An ectomycorrhizal fungus alters sensitivity to jasmonate, salicylate, gibberellin, and ethylene in host roots. Plant Cell Environ. 43:1047-1068.

Baum, C., Hrynkiewicz, K., Szymanska, S., Vitow, N., Hoeber, S., Fransson, P. M. A., and Weih, M. 2018. Mixture of Salix genotypes promotes root colonization with dark septate endophytes and changes P cycling in the mycorrhizosphere. Front. Microbiol. 9:1012.

Beckers, B., De Beeck, M. O., Weyens, N., Boerjan, W., and Vangronsveld, J. 2017. Structural variability and niche differentiation in the rhizosphere and endosphere bacterial microbiome of field-grown poplar trees. Microbiome 5: 25.

Berg, G., and Smalla, K. 2009. Plant species and soil type cooperatively shape the structure and function of microbial communities in the rhizosphere. FEMS Microbiol. Ecol. 68:1-13.

Bonito, G., Benucci, G. M. N., Hameed, K., Weighill, D., Jones, P., Chen, K. H., Jacobson, D., Schadt, C., and Vilgalys, R. 2019. Fungal-bacterial networks in the Populus rhizobiome are impacted by soil properties and host genotype. Front. Microbiol. 10:481.

Bonito, G., Hameed, K., Ventura, R., Krishnan, J., Schadt, C. W., and Vilgalys, R. 2016. Isolating a functionally relevant guild of fungi from the root microbiome of Populus. Fungal Ecol. 22:35-42.

Bonito, G., Reynolds, H., Robeson, M. S., Nelson, J., Hodkinson, B. P., Tuskan, G., Schadt, C. W., and Vilgalys, R. 2014. Plant host and soil origin influence fungal and bacterial assemblages in the roots of woody plants. Mol. Ecol. 23: 3356-3370.

Brockett, B. F. T., Prescott, C. E., and Grayston, S. J. 2012. Soil moisture is the major factor influencing microbial community structure and enzyme activities across seven biogeoclimatic zones in western Canada. Soil Biol. Biochem. 44: 9-20.

Chalot, M., Kytöviita, M. M., Brun, A., Finlay, R. D., and Söderström, B. 1995. Factors affecting amino acids uptake by the ectomycorrhizal fungus Paxillus involutus. Mycol. Res. 99:1131-1138.

Chaparro, J. M., Sheflin, A. M., Manter, D. K., and Vivanco, J. M. 2012. Manipulating the soil microbiome to increase soil health and plant fertility. Biol. Fertil. Soils 48:489-499.

Colin, Y., Nicolitch, O., Van Nostrand, J. D., Zhou, J. Z., Turpault, M. P., and Uroz, S. 2017. Taxonomic and functional shifts in the beech rhizosphere microbiome across a natural soil toposequence. Sci. Rep. 7:9604.

Cregger, M. A., Veach, A. M., Yang, Z. K., Crouch, M. J., Vilgalys, R., Tuskan, G. A., and Schadt, C. W. 2018. The Populus holobiont: Dissecting the effects of plant niches and genotype on the microbiome. Microbiome 6:31.

DeAngelis, K. M., Brodie, E. L., DeSantis, T. Z., Andersen, G. L., Lindow, S. E., and Firestone, M. K. 2009. Selective progressive response of soil microbial community to wild oat roots. ISME J. 3:168-178.

Dieryckx, C., Gaudin, V., Dupuy, J. W., Bonneu, M., Girard, V., and Job, D. 2015. Beyond plant defense: insights on the potential of salicylic and methylsalicylic acid to contain growth of the phytopathogen Botrytis cinerea. Front. Plant Sci. 6:859.

Dupont, P. Y., Eaton, C. J., Wargent, J. J., Fechtner, S., Solomon, P., Schmid, J., Day, R. C., Scott, B., and Cox, M. P. 2015. Fungal endophyte infection of ryegrass reprograms host metabolism and alters development. New Phytol. 208:1227-1240. 
Durand, A., Maillard, F., Foulon, J., Gweon, H. S., Valot, B., and Chalot, M. 2017. Environmental metabarcoding reveals contrasting belowground and aboveground fungal communities from Poplar at a $\mathrm{Hg}$ phytomanagement site. Microbiol. Ecol. 74:795-809.

Edwards, J., Johnson, C., Santos-Medellín, C., Lurie, E., Podishetty, N. K., and Bhatnagar, S., Eisen, J. A., and Sundaresan, V. 2015. Structure, variation, and assembly of the root-associated microbiomes of rice. Proc. Natl. Acad. Sci. 112(8):E911-E920.

Emerson, B. C., and Gillespie, R. G. 2008. Phylogenetic analysis of community assembly and structure over space and time. Trends Ecol. Evol. 23:619-630.

Escudié, F., Auer, L., Bernard, M., Mariadassou, M., Cauquil, L., Vidal, K., et al. 2018. FROGS: Find, rapidly, OTUs with galaxy solution. Bioinformatics 34 : 1287-1294.

Farrar, K., Bryant, D., and Cope-Selby, N. 2014. Understanding and engineering beneficial plant-microbe interactions: Plant growth promotion in energy crops. Plant Biotechnol. J. 12:1193-1206.

Fierer, N. 2017. Embracing the unknown: Disentangling the complexities of the soil microbiome. Nat. Rev. Microbiol. 15:579-590.

Foster, Z. S. L., Sharpton, T. J., and Grünwald, N. J. 2017. Metacoder: An R package for visualization and manipulation of community taxonomic diversity data. PLOS Comput. Biol. 13:1-15.

Frey-Klett, P., Grabaye, J., and Tarkka, M. 2007. The mycorrhizal helper bacteria revisited. New Phytol. 176:22-36.

Gehring, C. A., Mueller, R. C., and Whitham, T. G. 2006. Environmental and genetic effects on the formation of ectomycorrhizal and arbuscular mycorrhizal associations in cottonwoods. Oecologia 149:158-164.

Gehring, C. A., Sthultz, C. M., Flores-Rentería, L., Whipple, A. V., and Whitham, T. G. 2017. Tree genetics defines fungal partner communities that may confer drought tolerance. Proc. Natl. Acad. Sci. 114: 11169-11174.

Gottel, N. R., Castro, H. F., Kerley, M., Yang, Z., Pelletier, D. A., Podar, M., Karpinets, T., Uberbacher, E., Tuskan, G. A., Vilgalys, R., Doktycz, M. J., and Schadt, C. W. 2011. Distinct microbial communities within the endosphere and rhizosphere of Populus deltoides roots across contrasting soil types. Appl. Environ. Microbiol. 77:5934-5944.

Haas, D., and Keel, C. 2003. Regulation of antibiotic production in rootcolonizing Pseudomonas spp. and relevance for biological control of plant disease. Annu. Rev. Phytopathol. 41:117-153.

Haas, J. C., Street, N. R., Sjödin, A., Lee, N. M., Högberg, M. N., Näsholm, T., and Hurry, V. 2018. Microbial community response to growing season and plant nutrient optimisation in a boreal Norway spruce forest. Soil Biol. Biochem. 125:197-209.

Hacquard, S., and Schadt, C. W. 2015. Towards a holistic understanding of the beneficial interactions across the Populus microbiome. New Phytol. 205: 1424-1430.

Hoagland, D. C., and Arnon, D. I. 1950. The water culture method for growing plant without soil. California Agric. Exp. Circ. 337. The College of Agriculture University of California, Berkeley.

Jacoby, R., Peukert, M., Succurro, A., Koprivova, A., and Kopriva, S. 2017. The role of soil microorganisms in plant mineral nutrition-Current knowledge and future directions. Front. Plant Sci. 8:1617.

Lareen, A., Burton, F., and Schäfer, P. 2016. Plant root-microbe communication in shaping root microbiomes. Plant Mol. Biol. 90:575-587.

Lau, J. A., and Lennon, J. T. 2012. Rapid responses of soil microorganisms improve plant fitness in novel environments. Proc. Natl. Acad. Sci. 109:14058-14062.

Lebeis, S. L., Herrera Paredes, S., Lundberg, D. S., Breakfield, N., Gehring, J., McDonald, M. Malfatti, S., Glavina del Rio, T., Jones, C. D., Tringe, S. G., and Dangl, J. L. 2015. Salicylic acid modulates colonization of the root microbiome by specific bacterial taxa. Science 349:860-864.

Liao, H. L., Bonito, G., Rojas, J. A., Hameed, K., Wu, S., Schadt, C. W., Labbe, J. L., Tuskan, G., Martin, F. M., Grigoriev, I. V., and Vilgalys, R. 2019. Fungal endophytes of Populus trichocarpa alter host phenotype, gene expression and rhizobiome composition. Mol. Plant-Microbe Interact. 32: 853-864.

Lladó, S., López-Mondéjar, R., and Baldrian, P. 2017. Forest soil bacteria: Diversity, involvement in ecosystem processes, and response to global change. Microbiol. Mol. Biol. Rev. (MMBR) 81:e00063-16.

Lundberg, D. S., Yourstone, S., Mieczkowski, P., Jones, C. D., and Dangl, J. L. 2013. Practical innovations for high-throughput amplicon sequencing. Nat. Methods 10:999-1002.

Mader, M., Le Paslier, M. C., Bounon, R., Berard, A., Faivre Rampant, P., Fladung, M., Leple, J.-C., and Kersten, B. 2016. Whole-genome draft assembly of Populus tremula $\times$ Populus alba clone INRA 717-1B4. Silvae Genet. 65:74-79.
Martin, F., Boiffin, V., and Pfeffer, P. E. 1998. Carbohydrate and amino acid metabolism in the Eucalyptus globulus-Pisolithus tinctorius ectomycorrhiza during glucose utilization. Plant Physiol. 118:627-635.

Martínez-Medina, A., Appels, F. V. W., and van Wees, S. C. M. 2017. Impact of salicylic acid- and jasmonic acid-regulated defences on root colonization by Trichoderma harzianum T-78. Plant Signal. Behav. 12: e1345404.

Marupakula, S., Mahmood, S., and Finlay, R. D. 2016. Analysis of single root tip microbiomes suggests that distinctive bacterial communities are selected by Pinus sylvestris roots colonized by different ectomycorrhizal fungi. Environ. Microbiol. 18:1470-1483.

McMurdie, P. J., and Holmes, S. 2013. Phyloseq: An R package for reproducible interactive analysis and graphics of microbiome census data. PLoS One 8: e61217.

Meena, K. K., Sorty, A. M., Bitla, U. M., Choudhary, K., Gupta, P., Pareek, A., Singh, D. P., Prabha, R., Sahu, P. K., Gupta, V. K., Singh, H. B., Krishanani, K. K., and Minhas, P. S. 2017. Abiotic stress responses and microbe-mediated mitigation in plants: The omics strategies. Front. Plant Sci. 8:172.

Mello, A., and Balestrini, R. 2018. Recent insights on biological and ecological aspects of ectomycorrhizal fungi and their interactions. Front. Microbiol. 9: 216.

Mendes, R., Garbeva, P., and Raaijmakers, J. M. 2013. The rhizosphere microbiome: Significance of plant beneficial, plant pathogenic, and human pathogenic microorganisms. FEMS Microbiol. Rev. 37:634-663.

Mercado-Blanco, J., Abrantes, I., Caracciolo, A. B., Bevivino, A., Ciancio, A., Grenni, P., Hrynkiewicz, K., Kredics, L., and Proenca, D. N. 2018. Belowground microbiota and the health of tree crops. Front. Microbiol. 9: 1006.

Naylor, D., and Coleman-Derr, D. 2018. Drought stress and root-associated bacterial communities. Front. Plant Sci. 8:2223.

Nehls, U. 2008. Mastering ectomycorrhizal symbiosis: The impact of carbohydrates. J. Exp. Bot. 59:1097-1108.

Nguyen, N. H., Song, Z., Bates, S. T., Branco, S., Tedersoo, L., Menke, J., Schilling, J. S., and Kennedy, P. G. 2016. FUNGuild: An open annotation tool for parsing fungal community datasets by ecological guild. Fungal Ecol. 20: 241-248.

Oksanen J. 2015. Multivariate Analysis of Ecological Communities in R: Vegan tutorial.

Pena, R., and Polle, A. 2014. Attributing functions to ectomycorrhizal fungal identities in assemblages for nitrogen acquisition under stress. ISME J. 8: 321-330.

Pérez-Izquierdo, L., Zabal-Aguirre, M., Flores-Rentería, D., González-Martínez, S. C., Buée, M., and Rincón, A. 2017. Functional outcomes of fungal community shifts driven by tree genotype and spatial-temporal factors in Mediterranean pine forests. Environ. Microbiol. 19:1639-1652.

Pérez-Jaramillo, J. E., Mendes, R., and Raaijmakers, J. M. 2016. Impact of plant domestication on rhizosphere microbiome assembly and functions. Plant Mol. Biol. 90:635-644.

Pritchard, S. G. 2011. Soil organisms and global climate change. Plant Pathol. 60:82-99.

Quast, C., Pruesse, E., Yilmaz, P., Gerken, J., Schweer, T., Yarza, P., et al. 2013. The SILVA ribosomal RNA gene database project: Improved data processing and web-based tools. Nucleic Acids Res. 41:D590-D596.

R Core Team. 2016. R: A language and environment for statistical computing. R Foundation for Statistical Computing, Vienna, Austria. http://www.Rproject.org/

Raaijmakers, J. M., Paulitz, T. C., Steinberg, C., Alabouvette, C., and MoënneLoccoz, Y. 2009. The rhizosphere: A playground and battlefield for soilborne pathogens and beneficial microorganisms. Plant Soil 321:341-361.

Rohart, F., Gautier, B., Singh, A., and Lê Cao, K. A. 2017. mixOmics: An R package for 'omics feature selection and multiple data integration. PLOS Comput. Biol. 13:e1005752.

Shakya, M., Gottel, N., Castro, H., Yang, Z. K., Gunter, L., Labbé, J., Muchero, W., Bonito, G., Vilgalys, R., Tuskan, G., Podar, M., and Schadt, C. W. 2013. A multifactor analysis of fungal and bacterial community structure in the root microbiome of mature Populus deltoides trees. PLoS One 8:e76382.

Smith, S. E., and Read, D. J. 2008. Mycorrhizal Symbiosis, 3rd ed. Academic Press, New York.

Solomon, P. S., Water, O. D., and Oliver, R. P. 2007. Decoding the mannitol enigma in filamentous fungi. Trends Microbiol. 15:257-262.

Timm, C. M., Carter, K. R., Carrell, A. A., Jun, S. R., Jawdy, S. S., Vélez, J. M., et al. 2018. Abiotic stresses shift belowground Populus-associated bacteria toward a core stress microbiome. mSystems 3:e00070-17. 
Timm, C. M., Pelletier, D. A., Jawdy, S. S., Gunter, L. E., Henning, J. A., Engle, N., Aufrecht, J., Gee, E., Nookaew, I., Yang, Z., Lu, T. Y., Tschaplinski, T. J., Doktycz, M. J., Tuskan, G. A., and Weston, D. J. 2016. Two poplarassociated bacterial isolates induce additive favorable responses in a constructed plant-microbiome system. Front. Plant Sci. 7:497.

Tschaplinski, T. J., Plett, J. M., Engle, N. L., Deveau, A., Cushman, K. C., Martin, M. Z., Doktycz, M. J., Tuskan, G. A., Brun, A., Kohler, A. and Martin, F. 2014. Populus trichocarpa and Populus deltoides exhibit different metabolomic responses to colonization by the symbiotic fungus Laccaria bicolor. Mol. Plant-Microbe Interact. 27:546-556.

Tuskan, G. A., DiFazio, S., Grigoriev, I., Hellsten, U., Putnam, N., and Ralph, S. 2006. The genome of black cottonwood, Populus trichocarpa (Torr. \& Gray). Science 313:1596-1604.
Uroz, S., Buée, M., Deveau, A., Mieszkin, S., and Martin, F. 2016. Ecology of the forest microbiome: Highlights of temperate and boreal ecosystems. Soil Biol. Biochem. 103:471-488.

Van Der Heijden, M. G. A., Bardgett, R. D., and Van Straalen, N. M. 2008. The unseen majority: Soil microbes as drivers of plant diversity and productivity in terrestrial ecosystems. Ecol. Lett. 11:296-310.

Veach, A. M., Morris, R., Yip, D. Z., Yang, D. K., Engle, N. L., Cregger, M. A., Tschaplinski, T. J., and Schadt, C. W. 2019. Rhizosphere microbiomes diverge among Populus trichocarpa plant-host genotypes and chemotypes, but, it depends on soil origin. Microbiome 7:76.

Wang, Q., Garrity, G. M., Tiedje, J. M., and Cole, J. R. 2007. Naïve Bayesian classifier for rapid assignment of rRNA sequences into the new bacterial taxonomy. Appl. Environ. Microbiol. 73:5261-5267. 